\title{
FUNDAMENTAL INVESTIGATIONS ON THE MACHINABILITY OF ADDITIVELY MANUFACTURED MULTI-MATERIALS
}

\author{
T.Kelliger $^{1 *}$, D.Schraknepper ${ }^{1}$, T.Bergs $^{1,2}$ \\ ${ }^{1}$ Laboratory for Machine Tools and Production Engineering (WZL) of RWTH Aachen University, Aachen, Germany \\ ${ }^{2}$ Fraunhofer Institute for Production Technology (IPT), Aachen, Germany \\ ${ }^{\star}$ Corresponding author; e-mail: t.kelliger@wzl.rwth-aachen.de
}

\begin{abstract}
Additively manufactured multi-materials promise unique combinations of different material properties. However, the machining behavior of these materials is widely unknown. In this study, fundamental investigations on chip formation and morphology, cutting force, workpiece temperature after cutting and surface quality were conducted in orthogonal cutting experiments. Additively manufactured test specimens made out of 316L stainless steel processed by Laser Powder Bed Fusion (LPBF), and the nickel-based alloy Inconel 718 processed by wire-based Laser Metal Deposition (LMD-w) were machined. Investigations were conducted with single- and multi-material combinations as well as porous $316 \mathrm{~L}$ material. Besides, conventional cast material was machined in order to draw a relative comparison. The results showed significant changes in chip formation and cutting forces between cast and additively manufactured materials, especially for Inconel 718 . These differences can be attributed to the changed microstructure and material properties. For two-component multi-materials, the connection area between the materials acted as a defect only to a limited extent. It was shown that the main influence evoke from the cutting direction in relation to the build-up direction of the specimen.
\end{abstract}

\section{Keywords:}

Machinability; Additive Manufacturing; Multi-material; Porous Material; Laser Powder Bed Fusion, Laser Metal Deposition; 316L; 1.4404; Inconel 718; Chip Formation; Cutting Force

\section{INTRODUCTION}

The combination of the additive manufacturing (AM) techniques Laser Powder Bed Fusion (LPBF) and wirebased Laser Metal Deposition (LMD-w) allows unique combinations of different material properties within one component. Thus, multi-materials as well as porous components can be manufactured with precisely adjusted characteristics such as local hardness, damping behavior or tensile strength. As additively manufactured components have to exhibit a low and well defined surface roughness as well as geometrical accuracy, the functional surfaces have to be machined as one step of the post-processing process chain. So far, the machinability of these porous structures and multi-materials built from powder or wire-based laser assisted additive manufacturing techniques has only been investigated to a limited extend.

So far, research has focused on the investigation of the machinability of single-component additively manufactured materials with different build-up directions, heat treatments and microstructures. Alonso et al. [Alonso 2020] investigated the influence of wire arc additive manufacturing on the machinability in milling and drilling of TiAl6V4 parts, measuring cutting forces and chip form. The authors found that the AM material caused higher cutting torque and thrust because of the augmented mechanical properties of the AM material. Lizzul et al. [Lizzul 2020] observed a high dependency of the build-up direction relative to the cutting direction on tool wear in LPBFmanufactured TiAl6V4 specimens. The authors explain the findings with the anisotropic microstructure and the grain growth along the build-up direction. This led to an increase in tool wear up to $40 \%$ when milling specimens with a cutting direction $90^{\circ}$ compared to $0^{\circ}$ with respect to the horizontal plane of the powder bed. The chip shape did only differ to a limited extend depending on the build-up direction of the machined workpieces. Shunmugavel et al. [Shunmugavel 2017] conducted orthogonal cutting experiments on LPBF-manufactured TiAl6V4 test samples with different build-up directions. The authors detected higher cutting forces for the AM material compared to wrought material. Higher chip curling occurred when cutting perpendicular to the horizontal plane of the powder bed because of the grain growth direction. Grove et al. [Grove 2018] drew a comparison between as-built and heat treated Ti-5553 manufactured by LPBF. Higher tool wear occurred in heat-treated specimens due to an increased hardness and higher cutting forces. Conventional and as-built AM material showed similar wear mechanisms. A serrated chip was obtained machining conventional and heat-treated AM material, whereas the as-built material produced a nearly 
continuous chip. Bai et al. [Bai 2020] investigated the machinability of $A 131$ steel produced by directed energy deposition (DED). A change in microstructure, higher hardness, higher cutting forces and increased tool wear compared to conventional hot-rolled material were found. The chip formation changed to a finer serration in the AM material. Lopes et al. [Lopes 2020] conducted milling experiments on HSLA steel produced by wire arc additive manufacturing. Karabulut et al. [Karabulut 2020] investigated the effect of LPBF-manufactured Inconel 718 in drilling experiments. As no comparison to a similar cast material was drawn, a direct valuation of the results for multi-material application appears difficult. Patel et al. [Patel 2019] machined LPBF-manufactured Inconel 625 in milling experiments, observing differences depending on the buildup direction. The authors measured lower peak forces with higher deviations for milling in horizontal direction in respect to the powder bed. They explain these findings with higher yield strength perpendicular to the build-up direction. A scan strategy of $90^{\circ}$ orientation of scan vectors in consecutive layers led to an increase in cutting forces compared to a scan strategy of $67^{\circ}$ orientation.

Only very few investigations focused on the influence of porous AM materials as well as a combination of different materials within one component on the machinability and the profound cutting mechanisms. In this work, the effect of AM multi-materials on the machinability in fundamental orthogonal cutting experiments was studied. Besides, porous structures were taken into consideration. Therefore, powder based 316L was processed in LPBF and wire based Inconel 718 was processed in LMD-w to manufacture different single- and two-component test specimen. The investigations focused on cutting forces, chip form and morphology as well as workpiece temperature after cutting for a wide range of cutting parameters.

\section{MATERIALS AND METHODS}

\subsection{Process combination LPBF and LMD-w}

At Fraunhofer-Institute for Laser Technology (ILT) in Aachen, Germany, a hybrid manufacturing machine was developed to combine the LPBF process with the LMD-w process (Fig. 1). The powder and wire base material can have substantially different characteristics. For the LPBF process, the machine is equipped with standard galvanometer scanners. A movable laser processing head is mounted on a gantry-based axes system for the LMD process. The wire is supplied coaxially. Thus, both AM techniques can be applied within one layer, avoiding setup times and allowing the fabrication of two-component multimaterials.

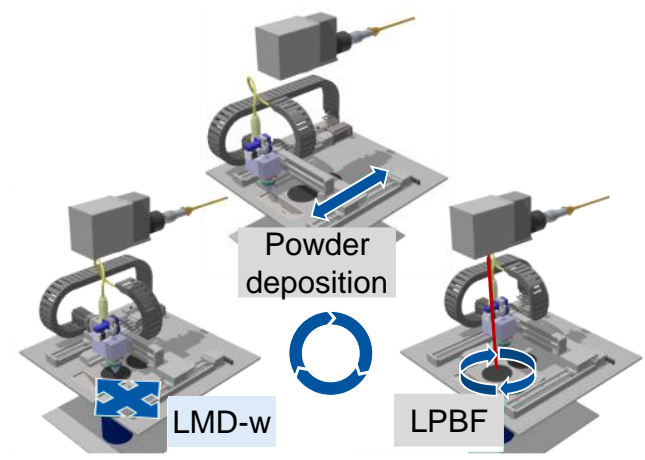

Fig. 1: Process combination for hybrid additive manufacturing (@) Fraunhofer-ILT)

\subsection{Investigated test specimens}

For the orthogonal cutting experiments, one-component and two-component test specimens were additively manufactured and compared to specimens from conventional cast material (dimensions: $60 \times 40 \times 3 \mathrm{~mm}^{3}$ ). Different combinations were investigated as shown in Fig. 2:

- Conventional cast material Inconel 718 "IN718 cast"

- Conventional cast material 316L "316L cast"

- LMD-w manufactured Inconel 718 "IN718 AM"

- LPBF manufactured 316L (relative density $99.98 \%$ ) "316L AM dense"

- LPBF manufactured 316L (relative density $96.76 \%$ ) "316L AM porous"

- Multi-material Inconel 718 and 316L (relative density $99.98 \%$ ) with process change in build-up direction ("top")

- Multi-material Inconel 718 and 316L (relative density $99.98 \%$ ) with process change in each layer ("side")

Due to the process characteristics, an adjusted relative density was set only in the LPBF process. The LMD-w manufactured specimens showed a relative density above $99.9 \%$. The relative part density was measured by means of optical light microscopy. All test specimens were fabricated with oversize and post-processed via surface grinding to facilitate the observations during the cutting experiments. The multi-material specimens "side" are named in accordance to the first material getting in contact with the cutting edge (e.g. Fig. 2 right side: specimen 1 (316L - IN718).

\section{One-component specimens}

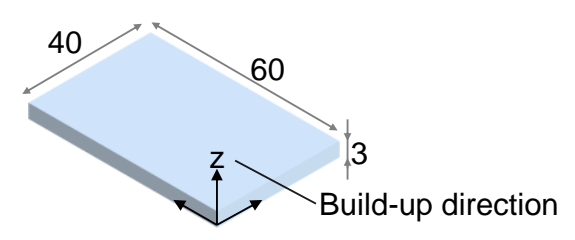

Two-component specimens

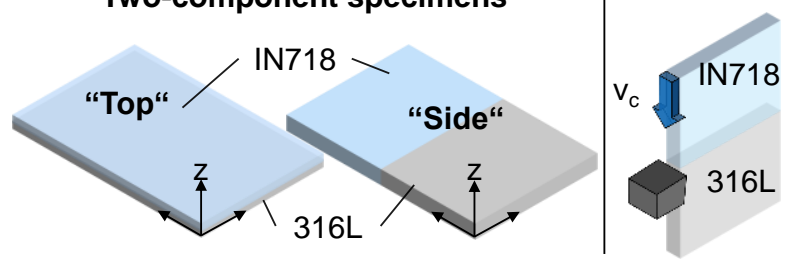

Fig. 2: Geometry of test specimens and material combinations for cutting experiments in orthogonal cutting

Specimens were manufactured using austenitic stainless steel powder AISI 316L (or 1.4404) from SANDVIK with a grain size between 15 - $45 \mu \mathrm{m}$ [Sandvik 2020] and nickelbased alloy wire Inconel 718 from United States Welding Corporation with a wire diameter of $0.8 \mathrm{~mm}$ [United States Welding Corporation 2020]. LPBF and LMD-w process parameters are indicated in Tab. 1.

The $316 \mathrm{~L}$ steel exhibits a high ductility and adhesion tendency with the cutting material [Naves 2013] as well as a lower thermal conductivity than unalloyed steel [Klocke 2018]. Inconel 718 is a difficult-to-cut material with an even lower thermal conductivity and a high tensile strength, which allows only low cutting speeds [Beer 2014]. The AM specimens were investigated in the as-built state without any heat treatment after the AM process. Thus, mechanical 
properties from the data sheets can differ to the real material characteristics [Brenne 2016].

Tab. 1: $L P B F$ and $L M D-w$ process parameters

\begin{tabular}{lcc} 
& LMD-w & LPBF \\
\hline Laser power & $1000 \mathrm{~W}$ & $275 \mathrm{~W}$ \\
\hline Feed rate/ & $0.3 \mathrm{~m} / \mathrm{min}$ & $1 \mathrm{~m} / \mathrm{s}$ (dense) \\
Scanning speed & $2 \mathrm{~m} / \mathrm{s}$ (porous) \\
\hline Wire feed rate & $0.56 \mathrm{~m} / \mathrm{min}$ & - \\
\hline Hatch distance & $1.3 \mathrm{~mm}$ & $0.1 \mathrm{~mm}$ \\
\hline Layer thickness & - & $0.05 \mathrm{~mm}$
\end{tabular}

In Fig. 3, the microstructures of all material combinations in form of etched micrographs are shown. Comparing conventional cast (a) and AM (b,c) 316 L material, the strong anisotropy of the microstructure as well as the melt tracks are visible. The high cooling rate due to the short lasermaterial interaction time implies a directionally cellulardendritic solidification morphology of the AM 316L samples (b) and (c) [Yusuf 2017]. Roettger et al. [Roettger 2016] reported a mean grain size of $25 \mu \mathrm{m}$ for a LPBF-fabricated component compared to $39 \mu \mathrm{m}$ for a cast component. The elongated grains grow along the build-up direction, but there is no preferred crystal growth direction. In image (c), partially grinded, unmelted powder particles are visible in the corners of the voids, resulting from an insufficient volume energy density during the LPBF process. The Inconel 718 in conventional form (d) has an austenitic microstructure. The melt tracks and microstructure of the Inconel (e) produced in LMD-w are significantly coarser than those produced in LPBF for 316L (b). Sample (e) exhibits a dendritic microstructure with the grains growing along the build-up direction [Brenne 2016]. The binding region between materials for all multi-material specimens shows only a low level of dilution between the two materials. Specimens (f) and (g) appear to be pore-free, while in specimen (h) small joint defects in the form of gas pores can be detected.

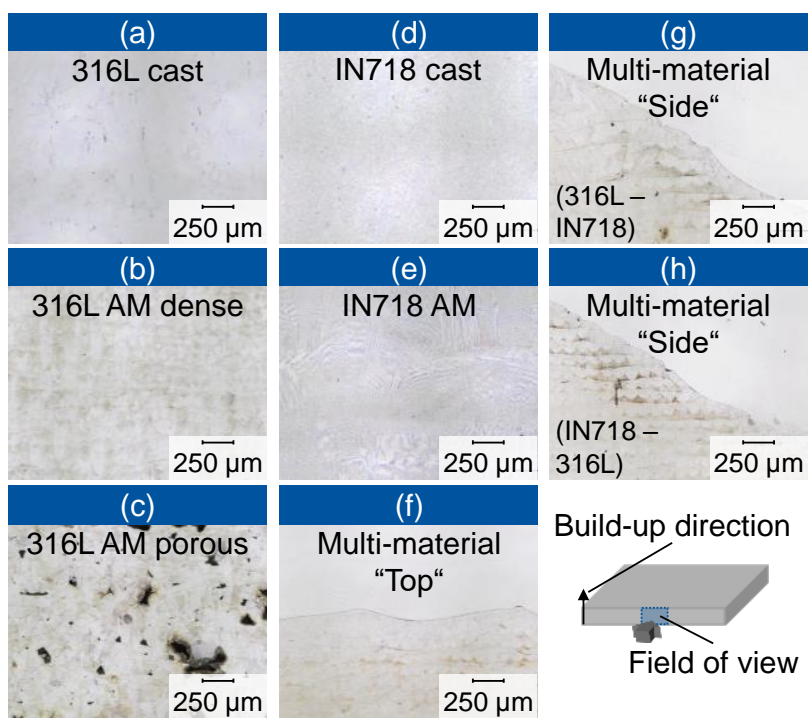

Fig. 3: Microstructure of all conventional and additively manufactured material variations

Hardness tests were performed on a testing machine Zwick ZHU250CL-a (3 indentations per specimen on the component surface marked in Fig. 3). As stated in Fig. 4, the average Vickers hardness of the 316L AM material exceeded the cast material by $42 \%$, while the cast Inconel surpassed the AM material hardness by $45 \%$. This might be due to the small grain size generated by the LPBF process compared to a very coarse microstructure caused by the LMD process.

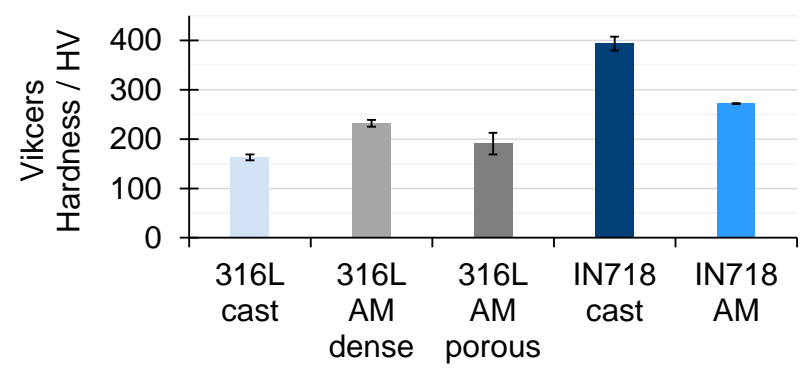

Fig. 4: Average Vickers hardness for one-component specimens (mean value and standard deviation)

\subsection{Experimental setup}

All orthogonal cutting experiments were conducted on an external broaching machine FORST RASX $2200 \times 800 \times$ $600 \mathrm{M} / \mathrm{CNC}$ using the conventional grooving inserts LCMF160608-0600-FT (grade CP500, grain size $2 \mu \mathrm{m}$, PVD-(Ti,Al)N + TiN coating, cutting edge radius $r_{\beta}=25 \mu \mathrm{m}$, clearance angle $\alpha=7^{\circ}$ ) from SECO TOOLS under dry conditions. The test specimens described in section 2.2 were clamped in the broaching stroke. The tool holder was mounted on a dynamometer Z21289 (sampling rate $20 \mathrm{kHz}$ ) from KISTLER on the machine table. Thus, cutting depth or undeformed chip thickness $h$ and cutting speed $v_{c}$ could be varied via table positioning and stroke speed. The experimental setup is shown in Fig. 5. Apart from force measurement, an infrared thermography camera FLIR Systems SC 7500 and a high-speed camera VISION Research Phantom v7.3 were used to measure the workpiece temperature after cutting and to observe the chip formation. The test specimens were coated with black spray paint to ensure an equal, idealized emissivity coefficient of $\varepsilon=1$. For each workpiece investigated, a new cutting insert was used. Tool wear was checked regularly. In these investigations, no significant tool wear influencing the measurements was detected. Chips were collected and analyzed by microscope.

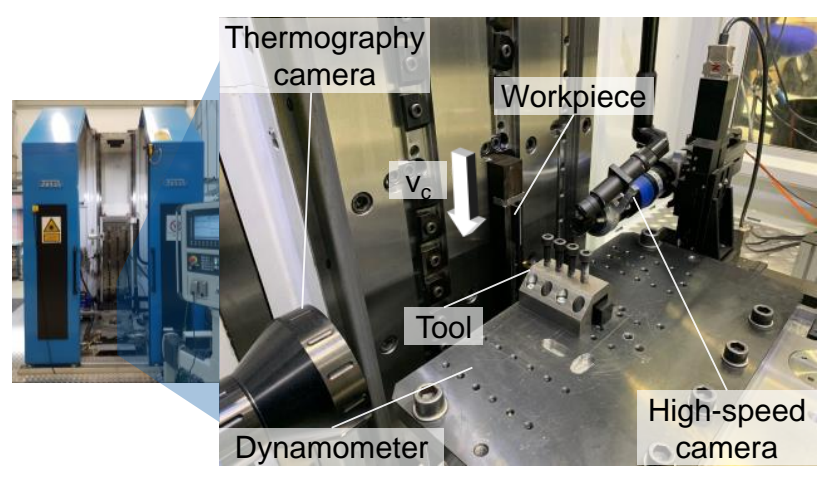

Fig. 5: Experimental setup for orthogonal cutting experiments

The cutting parameters cutting speed $v_{c}$ and undeformed chip thickness $h$ were varied in a wide range according to the common practice for the machined materials (Tab. 2). All multi-material specimens were processed with the parameters defined for Inconel 718 because of the reduced cutting speeds and cutting depths compared to 316L. In order to compare one- and two-component specimens, a common parameter set for all material variations was defined $\left(\mathrm{v}_{\mathrm{c}}=40 \mathrm{~m} / \mathrm{min}, \mathrm{h}=0.2 \mathrm{~mm}\right)$. For the multi-material combination "side", both arrangements with a different 
material to first get in contact with the cutting edge (316 IN718 as well as IN718 - 316L) were investigated.

Tab. 2: Cutting parameters for all material variations (' $x$ ' marked points were investigated)

\begin{tabular}{|c|c|c|c|c|c|}
\hline \multicolumn{9}{|c|}{$316 \mathrm{~L}$} \\
\hline \multicolumn{2}{|c|}{} & \multicolumn{5}{|c|}{$\mathrm{v}_{c} / \mathrm{m} / \mathrm{min}$} \\
\cline { 2 - 6 } \multicolumn{2}{|c|}{} & 40 & 80 & 100 & 120 \\
\hline$\xi$ & 0.1 & $x$ & & $x$ & \\
\cline { 2 - 6 }$\xi$ & 0.2 & & $x$ & $x$ & $x$ \\
\hline & 0.3 & & & $x$ & \\
\hline
\end{tabular}

\begin{tabular}{|c|c|c|c|c|}
\hline \multirow[t]{3}{*}{ IN718 } & \multirow{2}{*}{\multicolumn{4}{|c|}{ \& Multi-material }} \\
\hline & & & $/ \mathrm{mir}$ & \\
\hline & 20 & 30 & 40 & 50 \\
\hline 0.05 & & $x$ & & \\
\hline 0.1 & $x$ & $x$ & $x$ & $x$ \\
\hline 0.15 & & $x$ & & \\
\hline 0.2 & & $x$ & & \\
\hline
\end{tabular}

\section{RESULTS AND DISCUSSION}

As stated, a classification of the results was achieved comparing the measurements and observations of the AM and conventional cast materials.

\subsection{Cutting forces}

The cutting forces were evaluated by analyzing the cutting force $F_{C}$ and the normal cutting force $F_{c N}$ (Fig. 6). For the mean value, the range from $30 \%$ to $70 \%$ of the total signal of one cut of the unfiltered force signal was evaluated. In the following, the signal graphs are smoothed by calculating the moving average of 48 time periods. Two cuts were performed with each parameter combination.
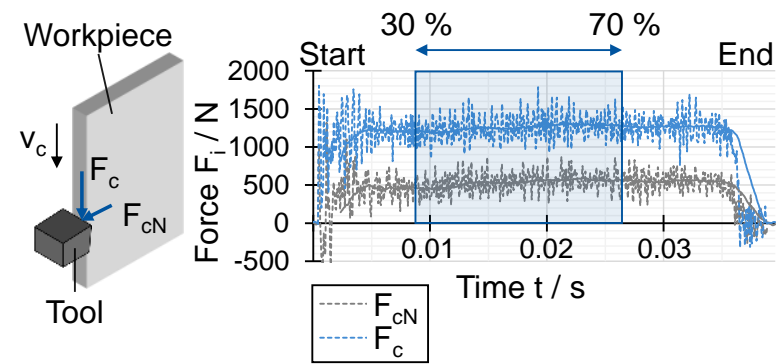

Fig. 6: Evaluation of the force measurement signal (exemplary for $316 \mathrm{~L}$ cast, $v_{c}=100 \mathrm{~m} / \mathrm{min}, h=0.2 \mathrm{~mm}$ ))

For $316 \mathrm{~L}$, the cutting forces $F_{c}$ for the $A M$ porous specimens were about $4 \%$ smaller than those of the AM dense specimens (maximum difference $51 \mathrm{~N}$ at $\mathrm{h}=0.3 \mathrm{~mm}$, $\mathrm{v}_{\mathrm{c}}=100 \mathrm{~m} / \mathrm{min}$ ), see Fig. 7. The cutting forces of the AM dense and cast material were comparable and only differed marginally (maximum difference $23 \mathrm{~N}$ at $\mathrm{h}=0.2 \mathrm{~mm}$, $\mathrm{v}_{\mathrm{c}}=100 \mathrm{~m} / \mathrm{min}$ ). The small differences between AM dense and conventional material were also measured for the cutting normal force $F_{\mathrm{CN}}$. The maximum difference between the $A M$ porous and the $A M$ dense specimen was $59 \mathrm{~N}$ ( $\mathrm{h}=0.3 \mathrm{~mm}, \mathrm{v}_{\mathrm{c}}=100 \mathrm{~m} / \mathrm{min}$ ).

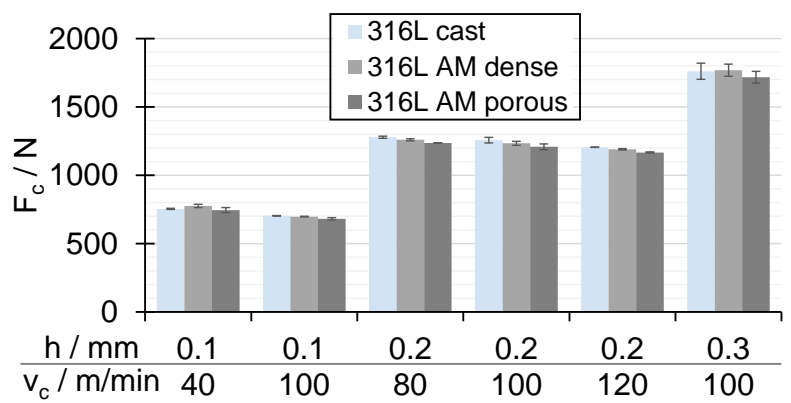

Fig. 7: Mean cutting force of $316 \mathrm{~L}$ cast and AM materials for different cutting parameters (mean value and standard deviation)

Comparing AM dense and porous material, the reduced cutting forces can be attributed to the reduced mechanical properties as well as to the porosity. Ilie et al. [llie 2017] showed for 316L LPBF specimens that the tensile strength decreases significantly with increasing porosity. A similar tendency was measured for the hardness (see Fig. 4). While the tensile strength of AM dense specimens was comparable to that of conventional cast $316 \mathrm{~L}$ material, investigations by Roettger et al. [Roettger 2020; Röttger 2016] showed a higher yield strength for the AM material (relative density $>99.9 \%$ ), which the authors attribute to the reduced grain size of the LPBF manufactured material compared to the cast material. Even though a higher hardness value was measured for the AM compared to the cast material (see Fig. 4), the cutting forces were comparable. This might result from the grain growth direction along the build-up direction.

At low cutting speeds $\left(\mathrm{V}_{\mathrm{c}}=40 \mathrm{~m} / \mathrm{min}\right), \mathrm{F}_{\mathrm{c}}$ and $\mathrm{F}_{\mathrm{cN}}$ increased for all material variations. This phenomenon of lower cutting forces with increasing cutting speed occurs due to the decrease in the materials strength with increasing temperature [Klocke 2018].

The recorded force measurement signals for $F_{c}$ and $F_{c N}$ (Fig. 8) of the cast and AM dense material were similar in shape and magnitude. An increase in force $F_{c}$ and $F_{C N}$ at approx. $0.015 \mathrm{~s}$ was observed for all material variations. This is due to the formation of a built-up edge occurring during the machining of austenitic steel materials with titanium-based coated tools. The risk of built-up edge formation increases with increasing ductility of the material. [Klocke 2018] According to Roettger et al. [Roettger 2020], ductility represented by elongation at break decreases with increasing porosity and is lower for AM material compared to cast material (AM: approx. $50 \%$ vs. cast: approx. $69 \%$ ). Due to lower build-up edge formation, the increase in the force measurement signal for the AM porous specimen is lower. It can be assumed that the porous material is less susceptible to built-up edge formation due to the defects in the microstructure, which prevent the forming chip from adhering to the cutting edge due to the interrupted material flow. The phenomenon described was also observed in a similar form at higher cutting speeds $v_{c}=120 \mathrm{~m} / \mathrm{min}$ and was visible in the high-speed camera recordings. The buildup edge formation appeared to be unstable and nonperiodically disappearing for all $316 \mathrm{~L}$ materials.

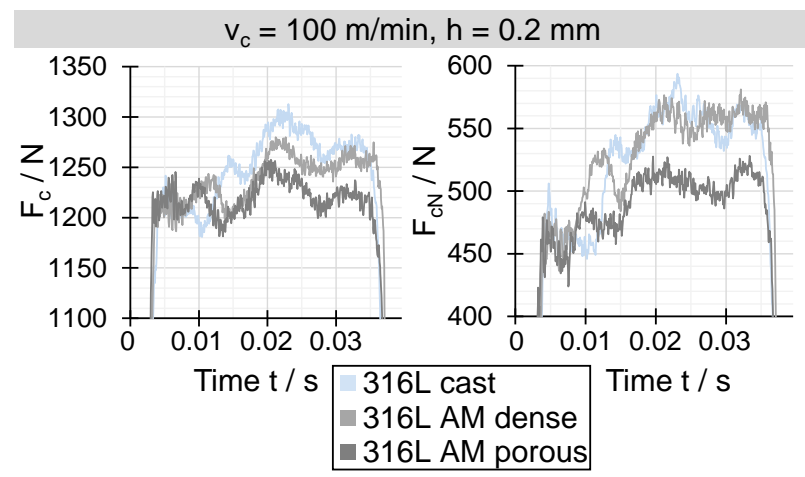

Fig. 8: Force measurement signal of $316 \mathrm{~L}$ cast and AM materials

In Fig. 9, the mean cutting forces $F_{c}$ for the cast and $A M$ Inconel materials as well as for all multi-material combinations are shown. For force evaluation of all multimaterial "side" specimens, the mean value was taken from the signal width equally distributed before and after the material transition according to the binding region location measured in the microscope images (see Fig. 12).

The cutting forces $F_{c}$ of the AM Inconel 718 were slightly lower compared to the cast material for most cutting 
parameters. This may be attributed to the higher hardness of the cast material (see Fig. 4). As the AM material did not undergo any heat treatment, mechanical properties are not comparable to those of heat treated cast material. Higher cutting forces may result from higher mechanical properties of the cast material [Hosseini 2019]. The higher ductility of the as-built AM material expressed by a higher elongation at fracture favors the adhesion phenomena occurring on the surface of the AM material (see Fig. 19).

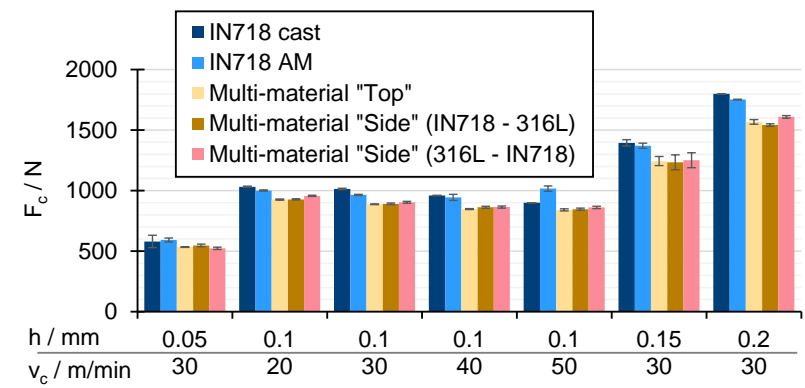

Fig. 9: Mean cutting force of Inconel 718 cast and AM materials and multi-material combinations for different cutting parameters (mean value and standard deviation)

The evaluation of the force measurement signal (see Fig. 10) showed significantly smaller fluctuations in the force signals for the cast Inconel 718 compared to the AM material. The AM layer-by-layer solidification leads to an inhomogeneous and anisotropic microstructure affecting the local hardness and material strength [Hosseini 2019]. $\mathrm{Ni}$ et al. [Ni 2017] observed a change in stress-strain diagrams of LPBF-manufactured Inconel 718 for a direction of loading in and perpendicular to the build-up direction. The authors explain the phenomenon with different fracture mechanisms. When loaded perpendicular to the build-up direction, softening and cracking occur at the grain boundaries. Thus, the strong fluctuation in the force measurement signal of the AM material as well as the chip shape presented in chapter 3.3 can be explained.

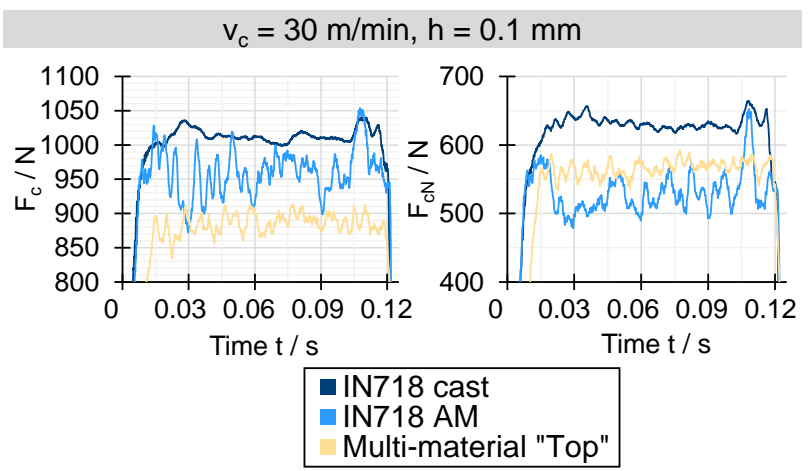

Fig. 10: Force measurement signal of IN718 cast and AM materials and multi-material "top" specimen

The described effect is shown schematically in Fig. 11. The grains of the cast material are isotropic and homogeneous in their shape, size and orientation. The grains of the AM material grow irregularly along the build-up direction. The force amplitudes of the signal increase in accordance with the observations of Sun et al. as the depth of cut increases [Sun 2009]. The signal of the multi-material "side" combination showed less fluctuation due to the proportion of $316 \mathrm{~L}$ material.

The mean cutting forces $F_{c}$ of all multi-material specimens were comparable and were slightly reduced compared to the single-material AM Inconel 718 specimen. This is due to the combination of the two materials within one specimen (lower cutting forces for AM 316L compared to AM Inconel 718 at low cutting speeds $\mathrm{v}_{\mathrm{c}}=30-50 \mathrm{~m} / \mathrm{min}$ ).

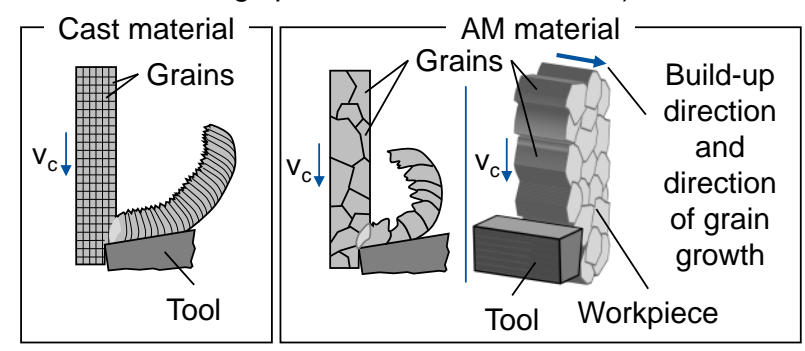

Fig. 11: Schematic representation of the chip formation for cast and AM Inconel 718 with effect on chip shape and cutting forces (based on [Bai 2020])

The binding region between the two materials was clearly visible in the force measurement signal for the multimaterial "side" specimens (see Fig. 12). A distinct drop in the signal for $F_{\mathrm{cN}}$ was observed for the combination IN718 - 316L. This could be due to material defects in the shape of pores in the binding region between materials, which were not visible in the micrographs (see Fig. 3). A clear transition zone was visible only for this combination on the rear side of the chip (see Fig. 18) as well as on the machined surface (see Fig. 19). The mean cutting forces of the multi-material specimens corresponded, with minor deviations, to the mean value of the cutting forces of the single-component $316 \mathrm{~L}$ AM dense and Inconel AM material.

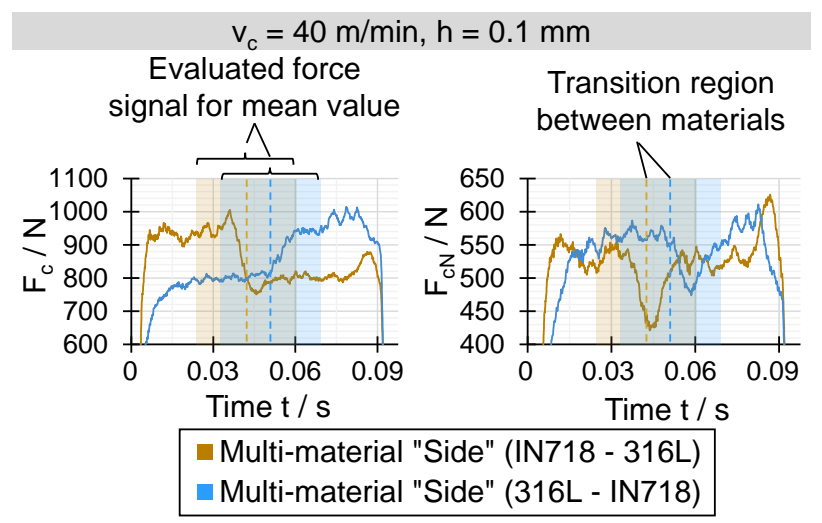

Fig. 12: Force measurement signal of multi-material "side" specimens. First material mentioned first reaches the cutting edge

\subsection{Workpiece temperature}

The maximum temperature $\mathrm{T}_{\max }$ measured on the workpiece surface directly after cutting was extracted from the thermographic images on the marked lines P1 and P2 for two consecutive images (see Fig. 13). The multi-material "side" specimens were not included in this analysis. Compared to the $316 \mathrm{~L} \mathrm{AM}$ material, the temperature for the $316 \mathrm{~L}$ cast material was higher for all cutting parameters and deviated by approx. $40^{\circ} \mathrm{C}$ for $\mathrm{h}=0.2$ and $\mathrm{h}=0.3 \mathrm{~mm}$. The effect could be explained by the higher ductility of the $316 \mathrm{~L}$ cast material leading to higher temperatures as well as a lower thermal conductivity of the homogenous austenitic microstructure. The maximum temperature was approx. $10{ }^{\circ} \mathrm{C}$ higher for the $316 \mathrm{~L}$ AM porous compared to the dense material. This can be traced back to a reduced thermal conductivity due to the porous microstructure [Alkahari 2012]. Even though cutting forces were lower for the Inconel 718 cast material, the maximum temperature was $10 \%$ to $70 \%$ higher compared to the AM material. This might result from heat accumulation in the AM material due to irregular chip formation as well as the coarse 
microstructure compared to the cast material. Further investigations have to be carried out in the future. For most of the cutting parameters, the multi-material "top" specimen showed similar maximum temperatures as the Inconel 718 AM sample.

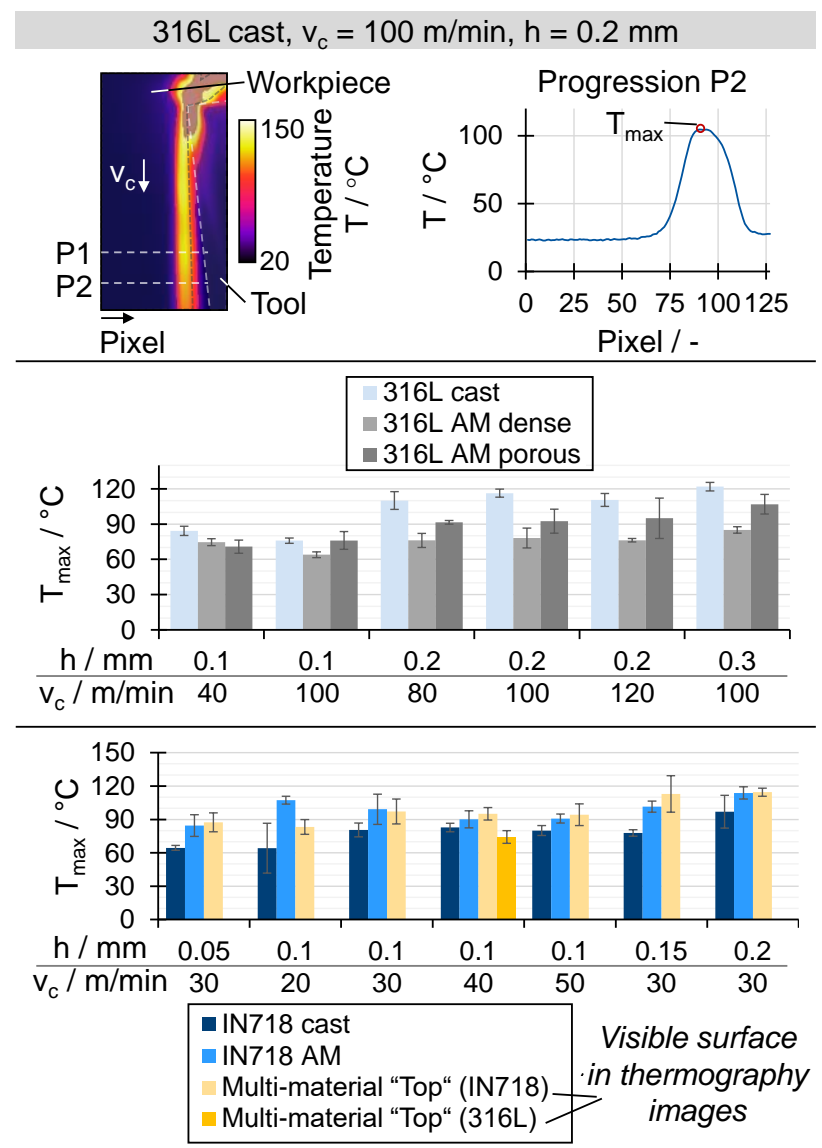

Fig. 13: Evaluation methodology and maximum workpiece temperature after cutting for different cutting parameters (mean value and standard deviation)

\subsection{Chip form and microstructure}

The evaluation of chips collected from cutting experiments with $\mathrm{v}_{\mathrm{c}}=40 \mathrm{~m} / \mathrm{min}$ and $\mathrm{h}=0.1 \mathrm{~mm}$ supports the observations of the cutting force measurements (Fig. 14). Minimum chip thickness $h_{c h, m i n}$ and maximum chip thickness $h_{c h, m a x}$ were measured and chip thickness ratio $\lambda_{h}$ and degree of segmentation $D_{s}$ calculated on one chip each.

Chips generated from $316 \mathrm{~L}$ showed a mixture of continuous and lamellar chip formation (Fig. 15). Chip thickness ratio, degree of segmentation and chip up-curl radius $r_{u}$ showed similar values. Adhesion on the rear side of the chip occured only on the $316 \mathrm{~L}$ cast chips similar to the observed surfaces in Fig. 19. This can be attributed to a lower ductility of the AM material compared to the cast material. The microstructure appeared finer for the AM chip, which is in accordance with Fig. 3. Squeezed voids were detected in the AM porous chip.

Chip shape and surface of the Inconel 718 cast and AM material differed (Fig. 16). In contrast to the continuous chip formation with a low degree of segmentation $(D s=0.12)$ for the cast material, the AM material showed a distinct irregular lamellar chip formation, a higher degree of segmentation $(D s=0.47)$ and a higher chip thickness ratio $\left(\lambda_{h}=2.15\right.$ vs. $\left.\lambda_{h}=1.74\right)$. The rear side of the AM chip showed adhesion equivalent to Fig. 19. At undeformed chip thicknesses $\mathrm{h}=0.15 \mathrm{~mm}$ and $\mathrm{h}=0.2 \mathrm{~mm}$, chip breakage occured for the AM material, which can be traced back to the coarse microstructure (see Fig. 11). The highly anisotropic microstructure was also visible in the micrograph. The higher chip compression can be explained with the increased ductility of the AM material.
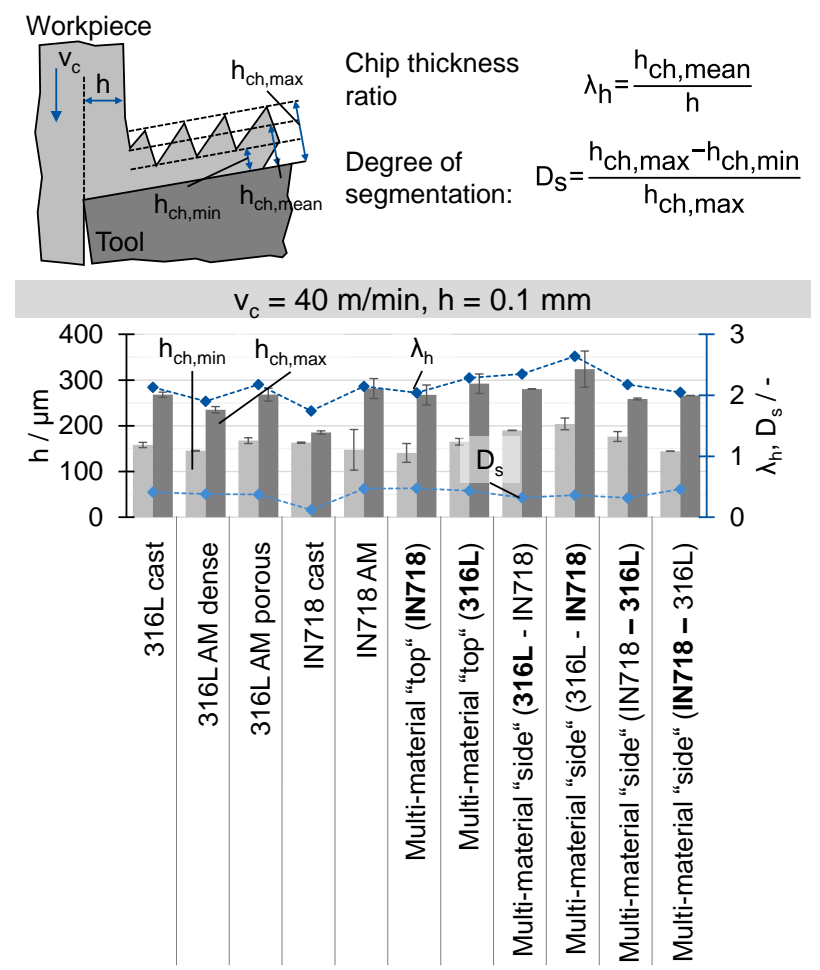

Fig. 14: Numerical chip evaluation for all material variations (mean value and standard deviation); the marked material is measured

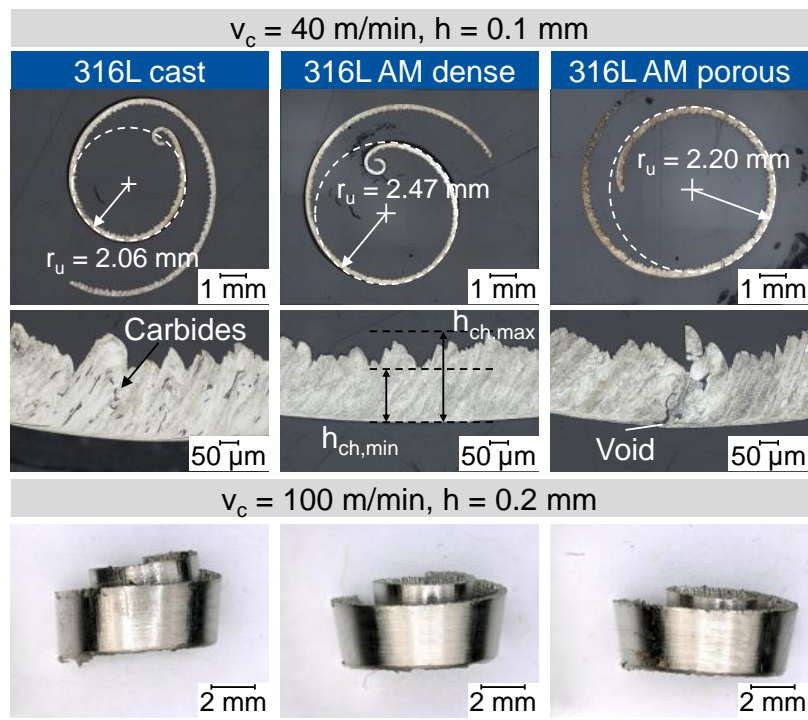

Fig. 15: Chip shape for all 316L single-component material combinations

For the multi-material "top" combination, the different chip thickness ratios of the materials caused a chip side-curling (Fig. 17). The chip up-curl radii were bigger than for the single-component materials. The chip curling of the Inconel AM proportion appeared more uniform than for the singlecomponent chip. A possible explanation could be the $316 \mathrm{~L}$ part stabilizing the coarse grains of the Inconel, which thus stick together at the grain boundaries. As a result, the material behavior during chip formation appears more ductile. 
The binding region between materials was clearly visible in the micrographs for the multi-material "side" combination (Fig. 18). On the rear side of the chip, the transition zone was only visible for the combination IN718 - 316L similar to Fig. 19, indicating a defect region with reduced mechanical properties. Regarding the chip shape and morphology, no big differences between single- and two-component material were detected for the multi-material "side" combinations.

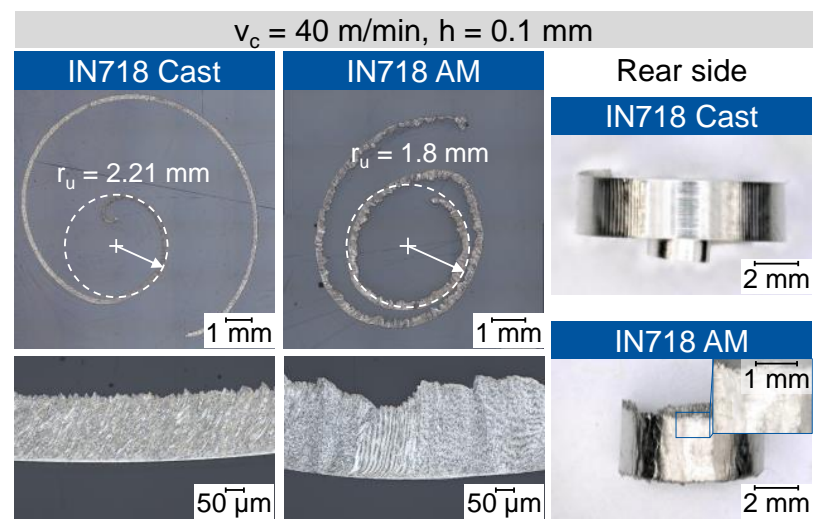

Fig. 16: Chip shape for all Inconel 718 single-component material combinations

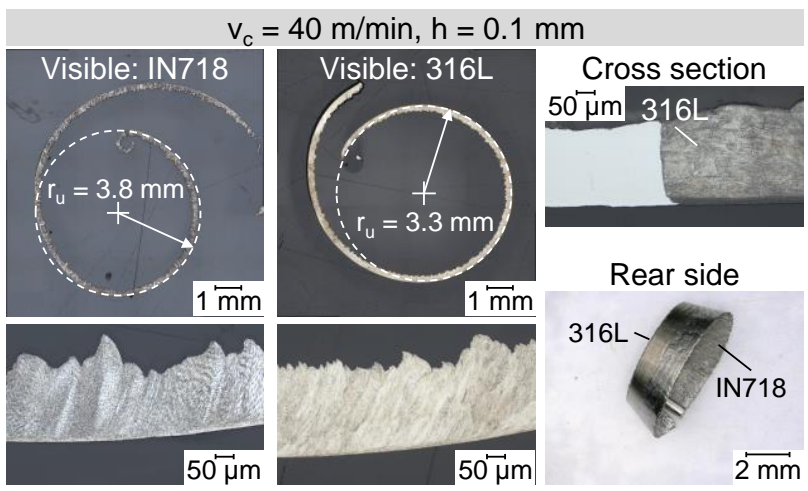

Fig. 17: Chip shape for multi-material "top"

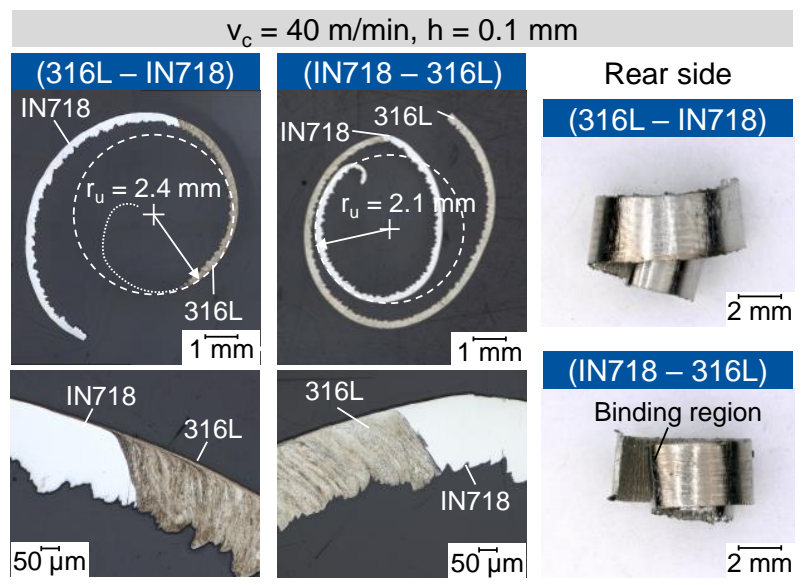

Fig. 18: Chip shape for multi-material "side" combinations

\subsection{Surface finish}

For the optical analysis of the machined surface, all specimens were machined with the same cutting parameters $\left(\mathrm{v}_{\mathrm{c}}=40 \mathrm{~m} / \mathrm{min}, \mathrm{h}=0.1 \mathrm{~mm}\right)$. The surface roughness was measured using an optical microscope ALICONA FocusG5. The average roughness value $\mathrm{Ra}$ and the average peak-to-valley height Rt were calculated from three evaluated lines (Fig. 19). As already stated above, the $316 \mathrm{~L}$ cast and Inconel 718 AM material exhibited adhesion.
Burr formation appeared on all $316 \mathrm{~L}$ samples with all examined cutting parameters, which is a common problem for austenitic steels [Klocke 2018]. Material defects in form of porosity were detected on specimen (c). The binding region between materials was clearly visible on the multimaterial specimens (f) and (h), while on (g) the transition could only be surmised.

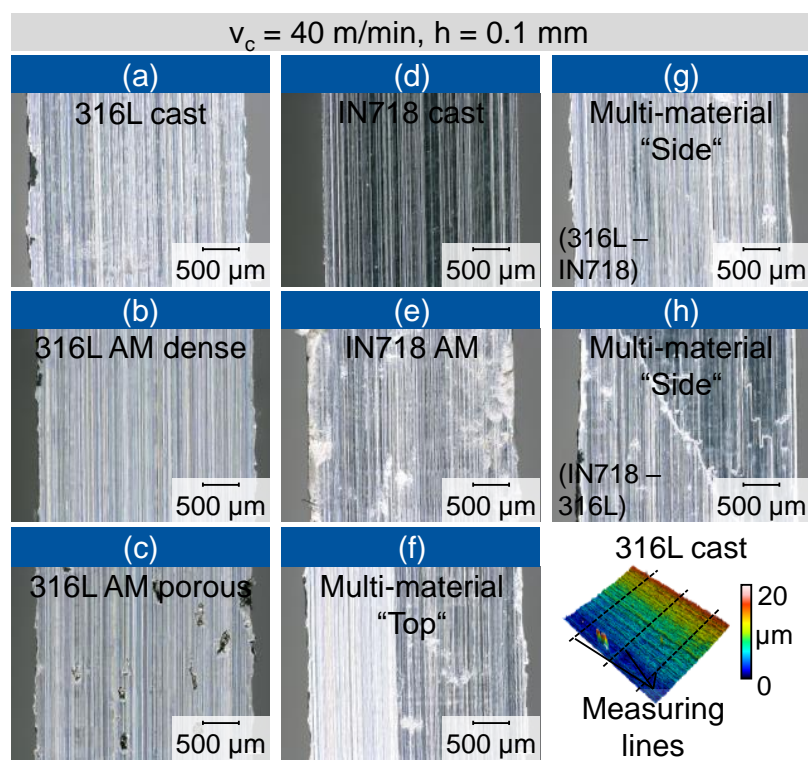

Fig. 19: Machined surfaces for all material variations

Surface roughness $\mathrm{Ra}$ and $\mathrm{Rt}$ showed slightly higher values for the Inconel 718 cast and AM material compared to the $316 \mathrm{~L}$ cast and AM dense test samples (Fig. 20). Due to the voids within the porous material, the values for $316 \mathrm{~L} \mathrm{AM}$ porous were more pronounced with $\mathrm{Ra}=3.6 \mu \mathrm{m}$ and $\mathrm{Rt}=51.1 \mu \mathrm{m}$. The multi-material combinations did not seem to effect the surface roughness. Possible differences might be more visible in a different experimental setup with a machining operation other than orthogonal cutting.

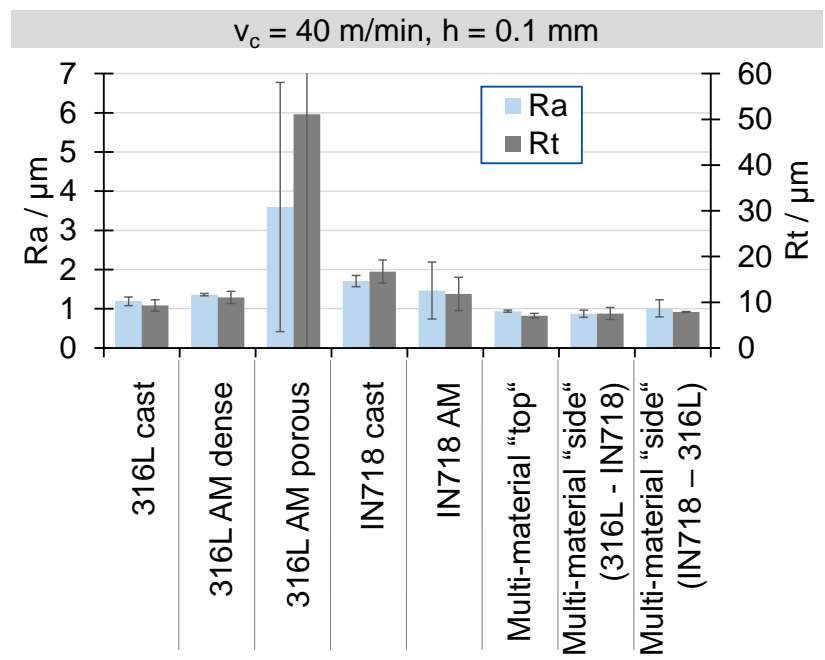

Fig. 20: Surface roughness for all material variations (mean value and standard deviation)

\section{CONCLUSION AND OUTLOOK}

The following conclusions can be drawn:

- Cutting forces and chip formation mechanisms for cast and AM (LPBF) 316L appeared to be comparable with a continuous, lamellar chip formation. The workpiece temperature for the porous material increased 
compared to the dense microstructure. The porosity leads to a reduction in thermal conductivity as well as mechanical strength.

- Results for cast and AM (LMD-w) Inconel 718 differed significantly. In contrast to the continuous chip formed by the cast material, the AM material generated an irregular lamellar chip also visible in strong fluctuations within the force measurement signal. The effects were traced back to the microstructure caused by additive manufacturing, with coarse grains growing along the bulid-up direction.

- For the two-component multi-material with process change in build-up direction, the Inconel proportion caused a more uniform continuous chip than for the single-component AM material due to the stabilizing effect of the $316 \mathrm{~L}$ proportion. Cutting forces were comparable to the mean value of the single-component materials.

- The binding region between materials for the multimaterial with process change in each layer was detected in the force measurement signal as well as in the high-speed videos and micrographs of the chips. The connection area acted as a defect only to a limited extend. The machinability of the respective material being in contact with the cutting edge was comparable to the single-component material.

This work builds the foundation for a general understanding of the fundamental material behavior in machining of $A M$ single- and multi-materials. Further studies must prove the observations for other machining operations such as turning or milling. A deeper understanding of the effects of different build-up directions in additively manufactured multi-materials should be acquired. Multi-material components can offer industrial potentials in shortening AM processing lead times as well as in combining local material properties for applications such as forming or cutting tools as well as conductive structures.

\section{ACKNOWLEDGMENTS}

The research shown in this paper was kindly supported by the members of the Technology Working Group (TAK) of the Laboratory for Machine Tools and Production Engineering (WZL) of RWTH Aachen University, Germany. The additively manufactured test specimens were fabricated by the Fraunhofer-Institute for Laser Technology (ILT) in Aachen, Germany with kind support from Tim Lantzsch and Dawid Ziebura.

\section{REFERENCES}

[Alkahari 2012] Alkahari, M. R. et al. Thermal Conductivity of Metal Powder and Consolidated Material Fabricated via Selective Laser Melting. Key Engineering Materials 523524, pp. 244-249.

[Alonso 2020] Alonso, U. et al. Experimental Investigation of the Influence of Wire Arc Additive Manufacturing on the Machinability of Titanium Parts. Metals 10, Vol 1, p. 24.

[Bai 2020] Bai, Y. et al. Investigation on the microstructure and machinability of ASTM A131 steel manufactured by directed energy deposition. Journal of Materials Processing Technology 276, p. 116410.

[Beer 2014] Beer, N. et al. Drilling of Inconel 718 with Geometry-modified Twist Drills. Procedia CIRP 24, pp. 4955.

[Brenne 2016] Brenne, F. et al. Microstructural design of Nibase alloys for high-temperature applications: impact of heat treatment on microstructure and mechanical properties after selective laser melting. Progress in Additive Manufacturing 1, Vol 3-4, pp. 141-151.

[Grove 2018] Grove, T. et al. Cutting mechanism and surface integrity in milling of Ti-5553 processed by selective laser melting. Journal of Mechanical Science and Technology 32, Vol 10, pp. 4883-4892.

[Hosseini 2019] Hosseini, E.,Popovich, V. A. A review of mechanical properties of additively manufactured Inconel 718. Additive Manufacturing 30, p. 100877.

[llie 2017] Ilie, A. et al. In-Built Customised Mechanical Failure of $316 \mathrm{~L}$ Components Fabricated Using Selective Laser Melting. Technologies 5, Vol 1, p. 9.

[Karabulut 2020] Karabulut, Y.,Kaynak, Y. Drilling process and resulting surface properties of Inconel 718 alloy fabricated by Selective Laser Melting Additive Manufacturing. Procedia CIRP 87, pp. 355-359.

[Klocke 2018] Klocke, F. Fertigungsverfahren 1. Zerspanung mit geometrisch bestimmter Schneide. Berlin, Heidelberg: Springer 2018.

[Lizzul 2020] Lizzul, L. et al. Influence of additive manufacturing-induced anisotropy on tool wear in end milling of Ti6Al4V. Tribology International 146, p. 106200.

[Lopes 2020] Lopes, J. G. et al. Effect of milling parameters on HSLA steel parts produced by Wire and Arc Additive Manufacturing (WAAM). Journal of Manufacturing Processes 59, pp. 739-749.

[Naves 2013] Naves, V.T.G. et al. Evaluation of the effect of application of cutting fluid at high pressure on tool wear during turning operation of AISI 316 austenitic stainless steel. Wear 302, Vol 1-2, pp. 1201-1208.

[Ni 2017] Ni, M. et al. Anisotropic tensile behavior of in situ precipitation strengthened Inconel 718 fabricated by additive manufacturing. Materials Science and Engineering A 701, pp. 344-351.

[Patel 2019] Patel, K. et al. Milling investigations and yield strength calculations for nickel alloy Inconel 625 manufactured with laser powder bed fusion process. Production Engineering 13, Vol 6, pp. 693-702.

[Roettger 2016] Roettger, A. et al. Comparison of microstructure and mechanical properties of $316 \mathrm{~L}$ austenitic steel processed by selective laser melting with hot-isostatic pressed and cast material. Materials Science and Engineering: A 678, pp. 365-376.

[Roettger 2020] Roettger, A. et al. Microstructure and mechanical properties of $316 \mathrm{~L}$ austenitic stainless steel processed by different SLM devices. Int J Adv Manuf Technol 108, Vol 3, pp. 769-783.

[Sandvik 2020] Sandvik Osprey 316L for Additive Manufacturing. Datasheet.

[Shunmugavel 2017] Shunmugavel, M. Influence of Build Orientation on Machinability of Selective Laser Melted Titanium Alloy-Ti-6Al-4V. International Journal of Materials and Metallurgical Engineering 11, Vol 8.

[Sun 2009] Sun, S. et al. Characteristics of cutting forces and chip formation in machining of titanium alloys. International Journal of Machine Tools and Manufacture 49, Vol 7-8, pp. 561-568.

[United States Welding Corporation 2020] United States Welding Corporation Turbaloy 718 - Data Sheet 5832. MCGrade GTQW Solid Bare Welding Wire Nickel Base.

[Yusuf 2017] Yusuf, S. et al. Investigation on Porosity and Microhardness of 316L Stainless Steel Fabricated by Selective Laser Melting. Metals 7, Vol 2 